\title{
Acúmulo de matéria seca e nutrientes pelo milho cultivado sob doses de formulados npk mineral e organomineral
}

\author{
Accumulation of dry matter and nutrients by corn grown under doses of formulated mineral and \\ organomineral npk \\ Acumulación de materia seca y nutrientes por maíz cultivado bajo dosis de formulado mineral y \\ organomineral npk
}

\section{Resumo}

O conhecimento da extração e acúmulo de nutrientes pelas plantas durante seu desenvolvimento auxilia na determinação das suas necessidades nutricionais e é relevante para aprimorar a recomendação de fertilizantes minerais e organominerais- Objetivou-se avaliar o efeito de doses de fontes de formulado NPK mineral e organomineral na produtividade de massa seca da parte aérea e no acúmulo de macronutrientes e micronutrientes pelo milho. $\mathrm{O}$ experimento foi realizado em vasos plásticos, dispostos a céu aberto, preenchidos com $25 \mathrm{~L}$ de solo, coletado de um 
Latossolo Vermelho distrófico, fase cerrado, na Fazenda Experimental do Instituto Federal Goiano, Campus Rio Verde - GO. O delineamento experimental utilizado foi de blocos ao acaso, em esquema fatorial 5x2, com quatro repetições. Os tratamentos foram cinco doses de formulado NPK 04-14-08 (0, 150, 300, 450, $600 \mathrm{~kg}^{-1}$ ha produto, equivalente para vaso) e duas fontes de fertilizantes: mineral e organomineral da formulação, 04-14-08. A colheita das plantas de milho foi realizada aos 75 dias após a semeadura, com corte do colmo rente ao solo. Nas plantas, foram realizadas avaliações de produtividade de massa seca da parte aérea e acúmulo de macronutrientes $(\mathrm{N}, \mathrm{P}, \mathrm{K}, \mathrm{Ca}, \mathrm{Mg}$ e $\mathrm{S})$ e micronutrientes $(\mathrm{Cu}, \mathrm{Fe}, \mathrm{Mn}$ e $\mathrm{Zn})$. A fonte organomineral proporcionou maior produtividade de matéria seca ao milho. $\mathrm{O}$ acúmulo de nutrientes seguiu a ordem decrescente $\mathrm{N}>\mathrm{K}>\mathrm{Mg}>\mathrm{Ca}>\mathrm{S}>\mathrm{P}>\mathrm{Fe}>\mathrm{Mn}>\mathrm{Zn}>\mathrm{Cu}$. A fonte organomineral, nas mesmas doses do formulado mineral, apresenta potencial de substituir as fontes minerais.

Palavras-chave: Extração de nutrientes; Fitomassa seca; Macronutrientes; Micronutrientes; Reciclagem de nutrientes.

\begin{abstract}
Knowledge of the extraction and accumulation of nutrients by plants during their development helps to determine their nutritional needs and is relevant to improve the recommendation for mineral and organomineral fertilizers. The objective of this study was to evaluate the effect of doses of sources of formulated mineral and organomineral NPK on the dry matter productivity of the aerial part and on the accumulation of macronutrients and micronutrients by corn. The experiment was carried out in plastic pots, arranged in the open, filled with $25 \mathrm{~L}$ of soil, collected from a dystrophic Red Latosol, closed phase, at the Experimental Farm of the Federal Goiano Institute, Rio Verde Campus GO. The experimental design used was randomized blocks, in a $5 \times 2$ factorial scheme, with four replications. The treatments were five doses of formulated NPK 04-14-08 $(0,150,300,450,600 \mathrm{~kg}$ ha-1 of the product, equivalent to pot) and two sources of fertilizers: mineral and organomineral formulation, 04-14-08. The corn plants were harvested at 75 days after sowing, with the cut of the stalk close to the soil. In the plants, evaluations of dry mass productivity of the aerial part and accumulation of macronutrients $(\mathrm{N}, \mathrm{P}, \mathrm{K}, \mathrm{Ca}, \mathrm{Mg}$ and $\mathrm{S}$ ) and micronutrients $(\mathrm{Cu}, \mathrm{Fe}, \mathrm{Mn}$ and $\mathrm{Zn})$ were carried out. The organomineral source provided higher dry matter productivity to corn. The accumulation of nutrients followed the decreasing order $\mathrm{N}>\mathrm{K}>\mathrm{Mg}>\mathrm{Ca}>\mathrm{S}>\mathrm{P}>\mathrm{Fe}>\mathrm{Mn}>\mathrm{Zn}>\mathrm{Cu}$. The organomineral source, in the same doses as the mineral formulation, has the potential to replace mineral sources.
\end{abstract}

Keywords: Nutrient extraction; Dry phytomass; Macronutrients; Micronutrientes; Nutrient recycling.

\title{
Resumen
}

El conocimiento de la extracción y acumulación de nutrientes por las plantas durante su desarrollo ayuda a determinar sus necesidades nutricionales y es relevante para mejorar la recomendación de fertilizantes minerales y organominerales. El objetivo de este estudio fue evaluar el efecto de dosis de fuentes de NPK mineral y organomineral formulado sobre la productividad de materia seca de la parte aérea y sobre la acumulación de macronutrientes y micronutrientes por el maíz. El experimento se realizó en macetas de plástico, dispuestas al aire libre, llenas de $25 \mathrm{~L}$ de tierra, recolectada de un Latosol Rojo distrófico, fase cerrada, en la Granja Experimental del Instituto Federal Goiano, Campus Río Verde - GO. El diseño experimental utilizado fue de bloques al azar, en un esquema factorial $5 \times 2$, con cuatro repeticiones. Los tratamientos fueron cinco dosis de NPK formulado 04-14-08 (0, $150,300,450,600 \mathrm{~kg}$ ha-1 de producto, equivalente a maceta) y dos fuentes de fertilizantes: formulación mineral y organomineral, 04-14- 08. Las plantas de maíz se recolectaron 75 días después de la siembra, con el tallo cerca del suelo. En las plantas se realizaron evaluaciones de la productividad de masa seca de la parte aérea y acumulación de macronutrientes ( $\mathrm{N}, \mathrm{P}, \mathrm{K}, \mathrm{Ca}, \mathrm{Mg}$ y S) y micronutrientes $(\mathrm{Cu}, \mathrm{Fe}, \mathrm{Mn}$ y $\mathrm{Zn})$. La fuente organomineral proporcionó una mayor productividad de materia seca al maíz. La acumulación de nutrientes siguió el orden decreciente $\mathrm{N}>\mathrm{K}>$ $\mathrm{Mg}>\mathrm{Ca}>\mathrm{S}>\mathrm{P}>\mathrm{Fe}>\mathrm{Mn}>\mathrm{Zn}>\mathrm{Cu}$. La fuente organomineral, en las mismas dosis que la formulación mineral, tiene el potencial de reemplazar las fuentes minerales.

Palabras clave: Extracción de nutrientes; Fitomasa seca; Macronutrientes; Micronutriente; Reciclaje de nutrientes.

\section{Introdução}

Os fertilizantes organominerais que se originam de uma mistura a partir de fertilizantes orgânicos (origem animal e vegetal) e fertilizantes minerais, surgem como alternativa para a melhoria da eficiência das adubações sem comprometer o desenvolvimento da planta e o meio ambiente (Ramos et al., 2017).

Segundo Levrero (2009) vários são os benefícios dos organominerais, sendo os mesmosdependentes principalmente de fatores ambientais e biológicos. Como efeitos positivos pode-se citar a maior eficiência no fornecimento dos nutrientes e melhoria no desenvolvimento radicular das plantas, na retenção de água e nas propriedades bio-físico-químicas do solo (Atkinson et Al., 2010; Jeffery et al., 2011), menor acidificação do solo, redução das perdas dos nutrientes, redução da erosão e menor custo operacional com aplicação conjunta do produto orgânico e mineral (Anderson et al., 2011). Além disso, espera-se o aumento da população de microrganismos no microambiente onde foi aplicado o fertilizante organomineral, devido ao 
fornecimento de energia advindo da fração orgânica, refletindo na maior ciclagem de nutrientes no ambiente de aplicação (Nelissen et al., 2013; Farrell et al., 2013). Desta forma, a aplicação de fertilizantes organominerais se torna uma estratégia viável para melhoraras propriedades do solo e consequentemente a produtividade agrícola (Benites et al., 2010; Farrel et al., 2014).

O uso de fertilizante organomineral corresponde a uma solução tecnológica, tanto sob o ponto de vista ambiental, como agronômico, pois combinam fertilizantes minerais (matéria prima minerais) e material orgânico (resíduos orgânicos). Desta forma, o uso dos fertilizantes organominerais pode ser uma alternativa inovadora na produção de grãos, pois podem diminuir os custos de produção, otimizar recursos naturais que não poderiam ser descartados e ainda gerar economia (Silva et al., 2006).

Adubo organomineral, de acordo a Instrução Normativa $N^{\circ}$ 23, de 13 de agosto de 2005, da Legislação Brasileira, é conceituado como "produto resultante da mistura física ou combinação de fertilizantes minerais e orgânicos". Entretanto no capítulo III da Instrução Normativa $\mathrm{N}^{\circ}$ 25, de 23 de julho de 2009, seção V art.8o, § $1^{\circ}$, é estabelecido às atuais especificações, garantias e características dos fertilizantes organominerais sólidos para a aplicação no solo. Segundo a referida IN os fertilizantes organominerais sólidos deverão apresentar, no mínimo: carbono orgânico: 8\%; CTC: 80 mmolc kg-1, 10\% de macronutrientes primários isolados (N, P, K) ou em misturas (NP, NK, PK ou NPK); 5\% de macronutrientes secundários e umidade máxima de 30\% (Brasil, 2009).

A recomendação das adubações é embasada nos estudos de resposta a fertilização e exigência nutricional da cultura, no caso do milho. Fator disponibilidade e solubilidade e da reação no fornecimento de nutrientes do adubo. Assim, faz-se necessário conhecer essas particularidades para recomendar mais precisamente doses adequada de fertilizantes para a cultura do milho, sob aspectos técnicos, econômicos e ambientais.

Algumas áreas de produção comercial de grãos em Latossolos do Cerrado apresentam cada vez mais elevada disponibilidade de $\mathrm{P}$ e $\mathrm{K}$ remanescente, devido ao efeito residual das adubações aplicadas nos cultivos, ao longo dos anos, principalmente sob sistema plantio direto (SPD) (Lourente et al., 2011; Santos et al., 2013; Wilda, 2014). Mesmo assim, os agricultores continuam adubando com quantidades fixas de N, P e K, por temerem a redução das produtividades, apesar de o nível de fertilidade do solo ser interpretado como alto em muitas lavouras, por desejarem altos rendimentos com a aplicação de doses extras de nutrientes (Hickmann, 2014).

A perspectiva é de aumento anual na demanda dos nutrientes em cerca de 4,3\% para $\mathrm{N}$ e $\mathrm{K} 2 \mathrm{O}$, e de 4,5\% para o P2O5, até o ano 2020 (Lopes et al., 2010). A fim de reduzir essa estatística, pode ser empregado com alternativa ao adubo organomineral, em que com a utilização do mesmo o produtor pode ter a redução de $35 \%$ a $40 \%$ a menos das fontes de nutrientes minerais, que pode representar uma redução significativa nos custos de produção (Benites, 2010).

Contudo, a escolha destas fontes deve estar atrelada à eficiência em suprir NPK para as plantas e a relação custo:benefício, de forma que o emprego de produtos de origem orgânica pode ter diversas vantagens, em especial, por alterar positivamente os atributos químicos do solo (Rodrigues et al., 2012). Assim, a mistura ou combinação de fertilizantes minerais e orgânicos resulta nos fertilizantes organomineral, os quais apresentam a finalidade de aumentar o teor de nutrientes dos solos e também aumentar a eficiência dos fertilizantes minerais (KiehL, 1999).

Os adubos orgânicos podem se constituir em alternativa para a preservação ambiental, pois reduzem a concentração de carbono atmosférico; possuem a função de condicionadores dos solos, que ajudam a estabilizar o pH, aumentam a quantidade de nutrientes e a matéria orgânica do solo (Bernardi et al., 2007; Brito; Santos, 2010).

A utilização de organomineral tem crescido nos últimos anos, principalmente pela redução dos custos em relação aos fertilizantes minerais, pela alta concentração em nutrientes e pelos efeitos benéficos que a matéria orgânica proporciona aos solos; assim, em alguns casos, podem ser aplicados na agricultura a substituição ou complementação da adubação mineral 
(Timossi et al., 2016; Malaquias; Sousa, 2017).

Partindo do conhecimento da absorção e do acúmulo de nutrientes na matéria seca e nos grãos durante o desenvolvimento da cultura, é possível determinar as épocas de maiores necessidades nutricionais das plantas de milho, além de avaliar a remoção de nutrientes do solo (Vitti et al., 1994; Castoldi et al., 2009), o que pode auxiliar na aplicação de doses mais adequadas de fertilizantes.

A planta de milho demonstra um crescimento expressivo, durante todo ciclo dos estádios fenológicos, que ocorre acúmulos de matéria seca, de nitrogênio, fósforo, magnésio e enxofre; seguindo até o início da maturação fisiológica, quando é atingido o acúmulo máximo (Pinho et al., 2009).

A extração total de nutrientes está relacionada com a quantidade de fitomassa produzida pela cultura e com a concentração de nutrientes presentes na palha e nos grãos. Assim, para maximizar a produtividade, necessita-se de doses, fontes e manejo adequado dos fertilizantes (França; Coelho, 2001; Peixoto, 2014).

As informações que se encontram disponíveis na literatura, quanto à utilização de adubação organomineral quando comparada a adubação mineral, ainda são incipientes e escassas.

O objetivo deste estudo foi avaliar o efeito de cinco doses e fontes de formulado mineral e organomineral, na produtividade de massa seca da parte aérea e no acúmulo de macronutrientes e micronutrientes pelo milho.

\section{Metodologia}

O estudo foi conduzido no Instituto Federal de Educação, Ciência e Tecnologia Goiano, Campus Rio Verde, GO, situado na latitude $17^{\circ} 48^{\prime} 19,1^{\prime \prime S}$ e longitude $50^{\circ} 54^{\prime} 15,8^{\prime \prime} \mathrm{W}$, com altitude média de 720 metros. O clima da região é classificado conforme Köppen (Castro Neto, 1982), como Aw (tropical), com chuva nos meses de outubro a maio, e com seca de junho a setembro. A temperatura média anual varia de 20 a $35{ }^{\circ} \mathrm{C}$ e as precipitações pluviométricas variam de 1.500 a $1.800 \mathrm{~mm}$ anuais. Na Figura 1, encontra-se o as precipitações pluviais e temperaturas, registradas durante a condução do experimento.

Figura 1. Precipitação pluvial e temperaturas registradas durante a condução do experimento, Rio Verde, Goiás, Safra 2016/17.

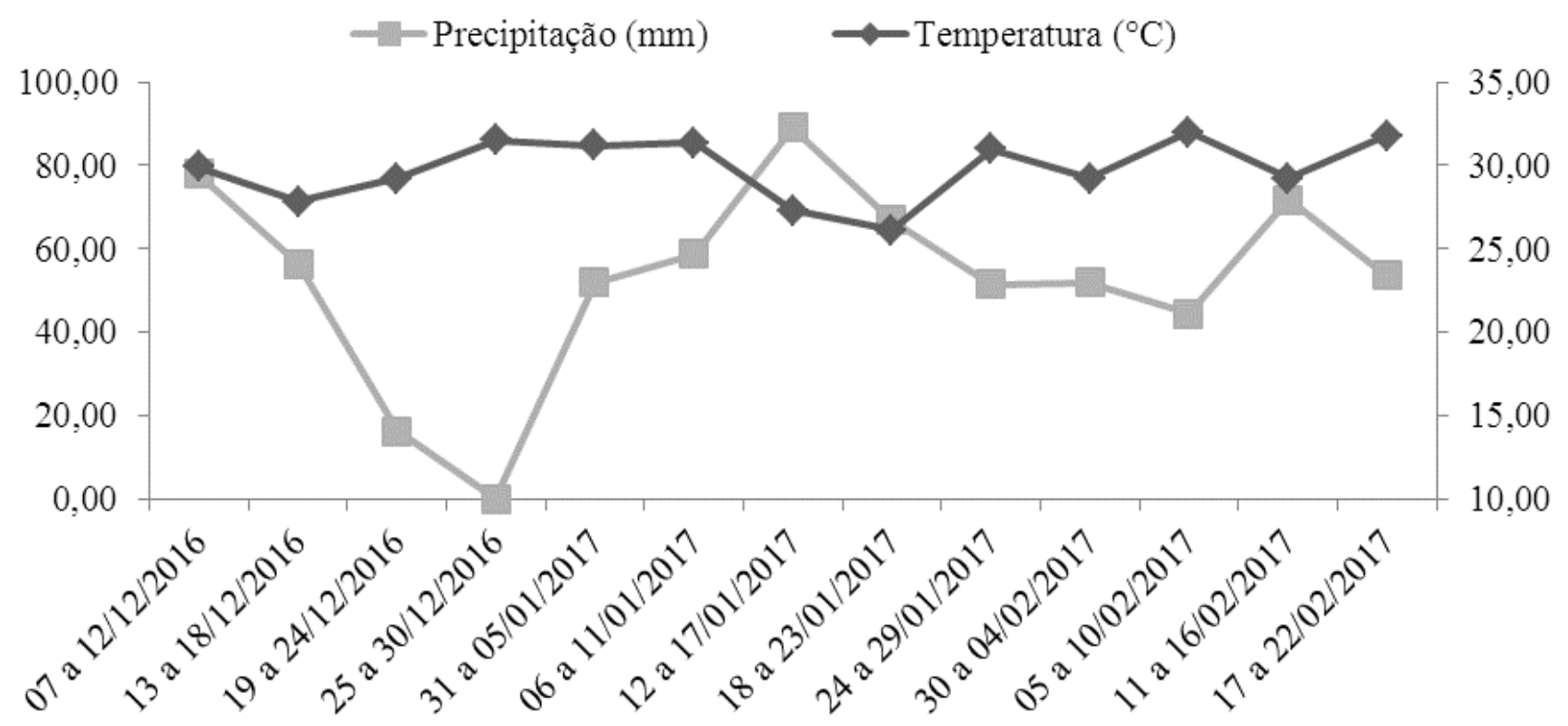

Fonte: Autores. 
O cultivo do milho foi realizado em vasos plástico, dispostos a céu aberto, contendo $25 \mathrm{~L}$ de solo, coletado, na camada de 0-0,20 m, de um Latossolo Vermelho distrófico, fase cerrado (Santos et al., 2018).

As análises químicas do solo foram realizadas conforme metodologias descritas em Raij et al. (2001) e apresentou os seguintes resultados: $\mathrm{pH}$ (CaCl2): M.O: $44 \mathrm{~g} \mathrm{~kg}^{-1} ; 5,2 ; \mathrm{P}$ (resina): $11 \mathrm{mg} \mathrm{dm}^{-3} ; \mathrm{K}: 1,1 \mathrm{mmolc} \mathrm{dm}{ }^{-3} ; \mathrm{Ca}: 19$ mmolc dm${ }^{-3} ; \mathrm{Mg}^{-14}$ mmolc dm ${ }^{-3}$; S: 6 mg dm-3 ${ }^{3}$ Al: 2 mmolc dm${ }^{-3}$; SB: 34,1 mmolc dm ${ }^{-3}$; CTC: 62,1 mmolc dm dm: $^{-3} 60 \%$, teor de argila: $42 \%$.

$\mathrm{O}$ delineamento experimental utilizado foi o de blocos ao acaso, analisado em esquema fatorial $5 \times 2$, com quatro repetições, constituídos por cinco doses de formulado 04-14-08 $\left(0,150,300,450,600 \mathrm{~kg} \mathrm{ha}^{-1}\right.$ do produto, equivalente para vaso) e duas fontes de fertilizantes: mineral e organomineral da formulação 04-14-08, totalizando 40 unidades experimentais, com mais 20 vasos referentes à bordadura.

A composição do fertilizante organomineral, proveniente da mistura da matéria-prima de cama de frango com fontes minerais, de acordo com a composição química do formulado NPK 04-14-08, apresentava os seguintes teores: N (\%) 04; P (\%) 14; K(\%) 08; Ca (\%) 7,6; Mg (\%) 44; S(\%) 2,12; Fe (\%) 0,3; Cu 121,8 ppm; Zn 278,4 ppm; Mn 135,7 ppm; MO (\%) 32.

Em 05/12/2016, foi realizada a semeadura manual do milho híbrido Simples P3844H, recomendado para cultivo de verão, em vasos preenchidos com $25 \mathrm{~L}$ de solo, distribuindo-se quatro sementes por vasos. Aos sete dias após a emergência (DAE), procedeu-se o desbaste, mantendo-se duas plantas de milho.

$\mathrm{Na}$ adubação de semeadura, foram aplicadas cinco doses dos formulados mineral e organomineral, de acordo com os respectivos tratamentos, cujo cálculo para as doses dos tratamentos foram estimadas para uma população de 70.000 plantas por hectare. Posteriormente, foram realizadas duas adubações com $\mathrm{N}$ em coberturas, na dose total de $100 \mathrm{~kg} \mathrm{ha}^{-1}$, ou seja $3,10 \mathrm{~g}$ vaso $^{-1}$, compreendendo: 50\% aos 20 DAE e 50\% aos 40 DAE. Nos tratamentos com a fonte mineral, usou-se a ureia (45\% de $\mathrm{N}$ ), e para fonte organomineral usou-se super $\mathrm{N}$ organomineral ( $45 \%$ de $\mathrm{N}$ ), cuja aplicação dos fertilizantes nitrogenados foi feita ao entorno da planta no vaso, seguida de irrigação.

A colheita foi realizada aos 75 DAE, mediante o corte das plantas de milho rente ao solo. A seguir, as mesmas foram acondicionadas em sacos de papel e enumeradas. Todo o material vegetal da parte aérea foi seco em estufa com circulação de ar forçada com temperatura de $65^{\circ} \mathrm{C}$, até massa constante e, após, as plantas foram pesadas, para a obtenção da matéria seca da parte aérea.

Posteriormente, as plantas de milho (folha, colmo, palha, sabugo e grãos) proveniente de cada parcela foram fragmentadas, separadamente, com auxílio de um facão. A seguir, foram retiradas amostras de cada parcela, que foram moídas em moinho tipo Wiley, as determinações químicas dos teores de macronutrientes (N, P, K, Ca, Mg e S) e micronutrientes (Cu, Fe, Mn, Zn), pelo Laboratório de Fertilidade do Solo do CENA/USP, cujas análises foram realizadas conforme Malavolta et al. (1997).

$\mathrm{O}$ acúmulo de nutrientes na matéria seca total da planta foi calculado por meio do produto (multiplicação) entre a concentração (teor) de cada nutriente na mesma pela matéria seca (g) x (concentração do nutriente na MS ( $\left.\mathrm{g} \mathrm{kg}^{-1}\right) / 1000$.

Para verificar o efeito das doses de adubação sobre as variáveis analisadas, os dados experimentais foram submetidos à análise de variância e quando detectados efeitos significativos pelo teste $\mathrm{F}$ a $5 \%$ de probabilidade, procedeu-se análise de regressão. O programa estatístico utilizado foi o SISVAR (Ferreira, 2011).

\section{Resultados e Discussão}

A análise de variância mostrou efeito significativo dos tratamentos doses e fontes de $\mathrm{N}$ sobre o acúmulo de matéria seca e de macronutrientes (fósforo, nitrogênio, potássio, cálcio, magnésio, enxofre), e de micronutrientes (cobre, ferro, manganês e zinco) para planta de milho (Tabela 1). 
Tabela 1. Resumo da análise de variância para as variáveis matéria seca, macronutrientes e micronutrientes na cultura do milho, em função de doses de formulados NPK mineral e organomineral.

\section{Quadrado Médio}

\begin{tabular}{|c|c|c|c|c|c|c|c|c|c|c|c|c|}
\hline \multirow[t]{2}{*}{ FV } & \multirow[t]{2}{*}{ GL } & \multicolumn{7}{|c|}{ Macronutrientes- } & \multicolumn{4}{|c|}{-Micronutrientes- } \\
\hline & & MS & $\mathrm{N}$ & $\mathrm{P}$ & $\mathrm{K}$ & $\mathrm{Ca}$ & $\mathrm{Mg}$ & $\mathrm{S}$ & $\mathrm{Cu}$ & $\mathrm{Fe}$ & $\mathrm{Mn}$ & $\mathrm{Zn}$ \\
\hline Fonte & 1 & $6733,9^{* *}$ & $0,0006^{\mathrm{ns}}$ & $0,007^{*}$ & $0,59^{* *}$ & $0,003^{\mathrm{ns}}$ & $0,08^{* *}$ & $0,03^{* *}$ & $0,006^{\mathrm{ns}}$ & $3684^{* *}$ & $0,22^{\mathrm{ns}}$ & $0,84^{\mathrm{ns}}$ \\
\hline Doses & 4 & $64256^{*}$ & $8,53^{* *}$ & $0,03^{* *}$ & $4,90^{*}$ & $0,80^{* *}$ & $1,04^{* *}$ & $0,055^{* *}$ & $0,29^{* *}$ & $4085^{* *}$ & $224,7^{* *}$ & $27,10^{* *}$ \\
\hline $\mathrm{F} \times \mathrm{D}$ & 4 & $1572,5^{*}$ & $0,10^{\mathrm{ns}}$ & $0,0009^{\mathrm{ns}}$ & $0,35^{*}$ & $0,021^{*}$ & $0,108^{* *}$ & $0,001^{*}$ & $0,012^{\mathrm{ns}}$ & $155,9^{\text {ns }}$ & $0,78^{\mathrm{ns}}$ & $0,11^{\mathrm{ns}}$ \\
\hline Bloco & 3 & 36 & 0,022 & 0,0008 & 0,04 & 0,003 & 0,006 & 0,0003 & 0,0017 & 15,45 & 1,66 & 0,13 \\
\hline Resíduo & 27 & 569 & 0,14 & 0,022 & 0,09 & 0,16 & 0,107 & 0,0006 & 0,005 & 242 & 3,63 & 0,60 \\
\hline $\mathrm{CV}(\%)$ & & 11 & 13 & 15 & 14 & 12 & 12 & 14 & 14 & 24 & 18 & 12 \\
\hline
\end{tabular}

${ }^{\text {ns }}$ não significativo, ${ }^{* *}$ significativo a $1 \%,{ }^{*}$ significativo a $5 \%$ de probabilidade segundo teste F. GL - Grau de Liberdade e CV - Coeficiente de Variação. Fonte: Autores.

O máximo acúmulo de matéria seca pelas plantas de milho sob a aplicação das doses do formulado NPK foi atingida com as doses de $600 \mathrm{~kg} \mathrm{ha}^{-1}$, cuja fonte organomineral apresentou um acúmulo de matéria seca de $319 \mathrm{~g} \mathrm{planta}^{-1}$, enquanto que com a fonte mineral foi de $282 \mathrm{~g} \mathrm{planta}^{-1}$, o que equivale a $12 \%$ de aumento na produtividade de matéria seca do milho em relação à adubação mineral (Figura 2). Resultados similares foram obtidos por Ourives et al. (2010) e Lana et al. (2014), que também verificaram maiores produtividades de matéria verde e seca em outras culturas, com o uso de fertilizante organomineral quando comparado ao mineral. No entanto, os resultados obtidos não se assemelham aos de Castoldi et al. (2011), onde não foram observadas diferenças estatísticas entre as adubações (mineral, orgânica e organomineral) para as variáveis massa de matéria seca de colmo, espiga, folhas, inflorescência e, consequentemente, de parte aérea. 
Figura 2. Acúmulo de matéria seca da parte aérea de plantas de milho, em função Interação das doses (A) mineral e organomineral e fontes (B) do formulado NPK.
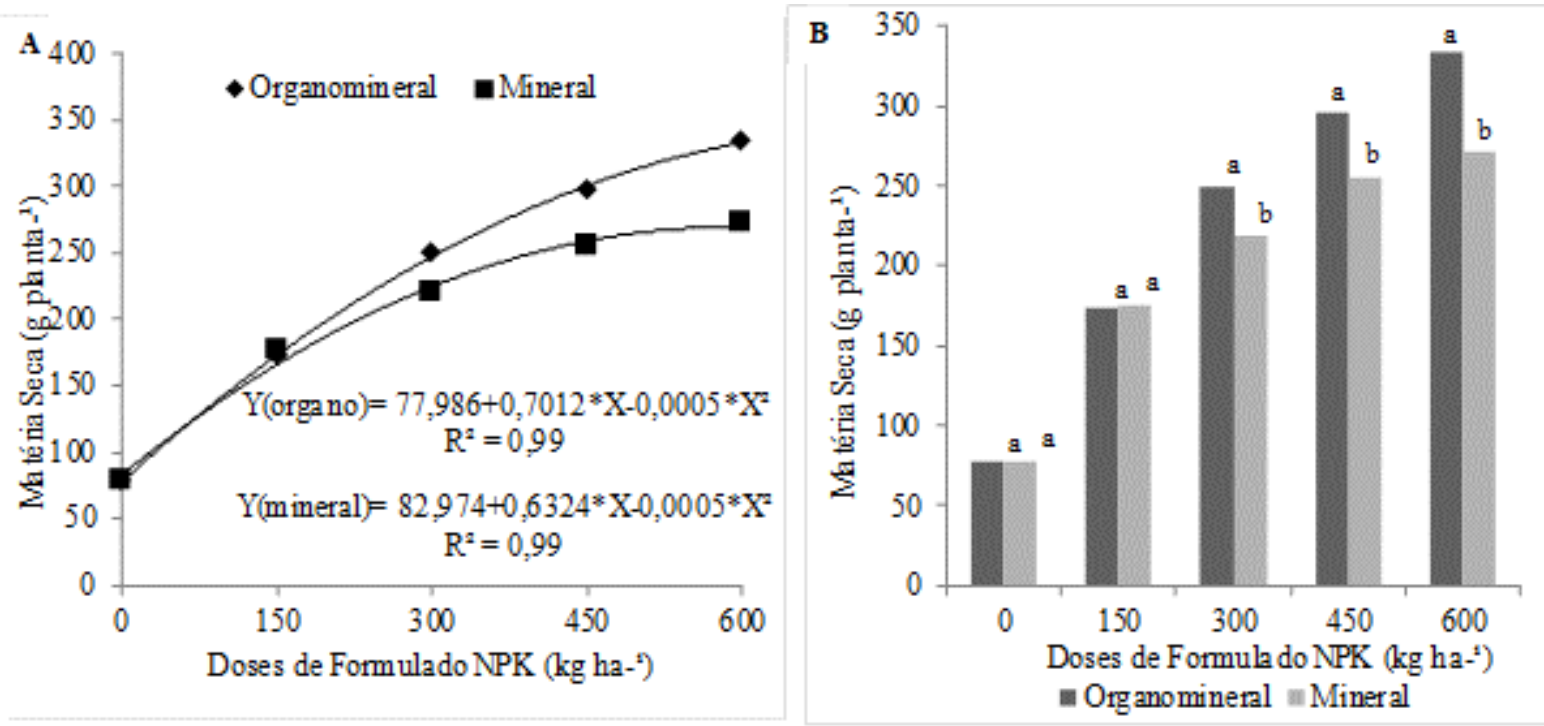

Médias seguidas com letra distintas na coluna, dentro da mesma dose, diferem entre si pelo teste de Tukey a 5\%. Fonte: Autores.

Com relação aos macronutrientes N, P e K acumulados na matéria seca do milho, para o N, as doses do formulado NPK elevaram o acúmulo deste nutriente até a dose de $600 \mathrm{~kg} \mathrm{ha}^{-1}$, em que com aplicação dessa dose foi atingida o máximo acúmulo de $128,8 \mathrm{~kg} \mathrm{ha}^{-1}$ de $\mathrm{N}$. Os aumentos corresponderam, respectivamente, a $68 \%$, 30\% e 7\% comparada às menores doses de NPK de 0, 150, 300 e $450 \mathrm{~kg} \mathrm{ha}^{-1}$ (Figura 3).

Figura 3. Acúmulo de nitrogênio da parte aérea de plantas de milho, em função das doses do formulado NPK.

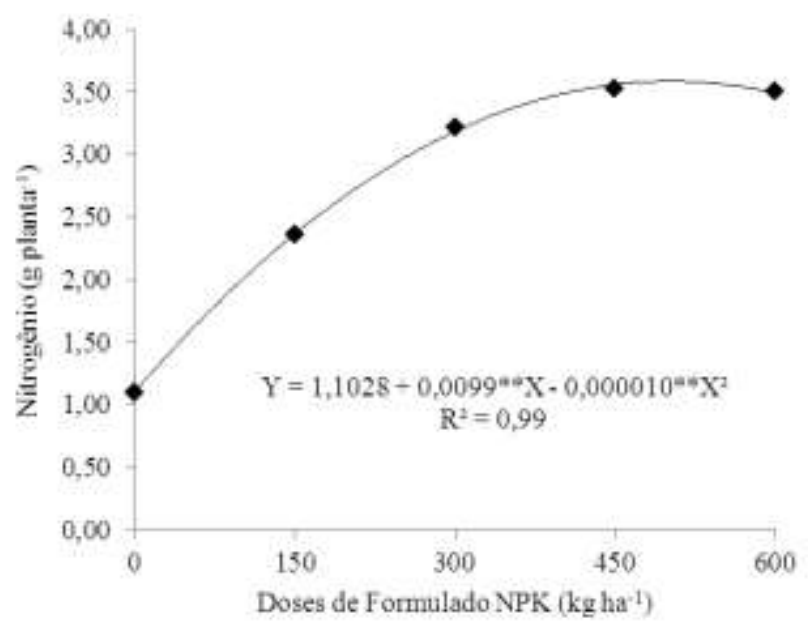

Fonte: Autores.

As distintas fontes se NPK não influenciaram no acúmulo de N, que não é condizente com as fontes utilizada, pois há diferença na solubilidade das mesmas, cuja fonte mineral possui alta solubilidade, enquanto que a fonte organomineral apresenta menor disponibilidade imediata, uma vez que depende da mineralização da fração orgânica para liberar os nutrientes, principalmente $\mathrm{N}$ e P. Tal fato, em parte, pode ser devido ao teor de matéria orgânica do solo, que era de $44 \mathrm{~g} \mathrm{~kg}^{-1}$, como descrito no item Material e Métodos; assim, possivelmente forneceu parte do $\mathrm{N}$ demandado pela planta, sobretudo na fase 
inicial, até mineralização da fonte organomineral. Em estudos realizados por Costa et al. (2011), foi obtido maior teor de N quando se utilizou a adubação mineral.

O acúmulo de fósforo em função das doses do formulado NPK elevaram o acúmulo de nutriente até a dose de $600 \mathrm{~kg}$ ha $^{-1}$, em que com a aplicação desta dose foi atingido máximo acúmulo, de aproximadamente $0,25 \mathrm{~g}_{\text {planta }}{ }^{-1}$. $\mathrm{O}$ acúmulo de fósforo máximo verificada na dose do formulado de $600 \mathrm{~kg} \mathrm{ha}^{-1}$, foi $65,34,13$ e $2 \%$ maior do que o observado nas doses de 0 , 150,300 e $450 \mathrm{~kg} \mathrm{ha}^{-1}$, respectivamente (Figura 4A).

Figura 4. Acúmulo de fósforo da parte aérea de plantas de milho em função das doses do formulado NPK (A). Médias para o fósforo em função das fontes do formulado NPK 04-14-08 mineral e organomineral (B).
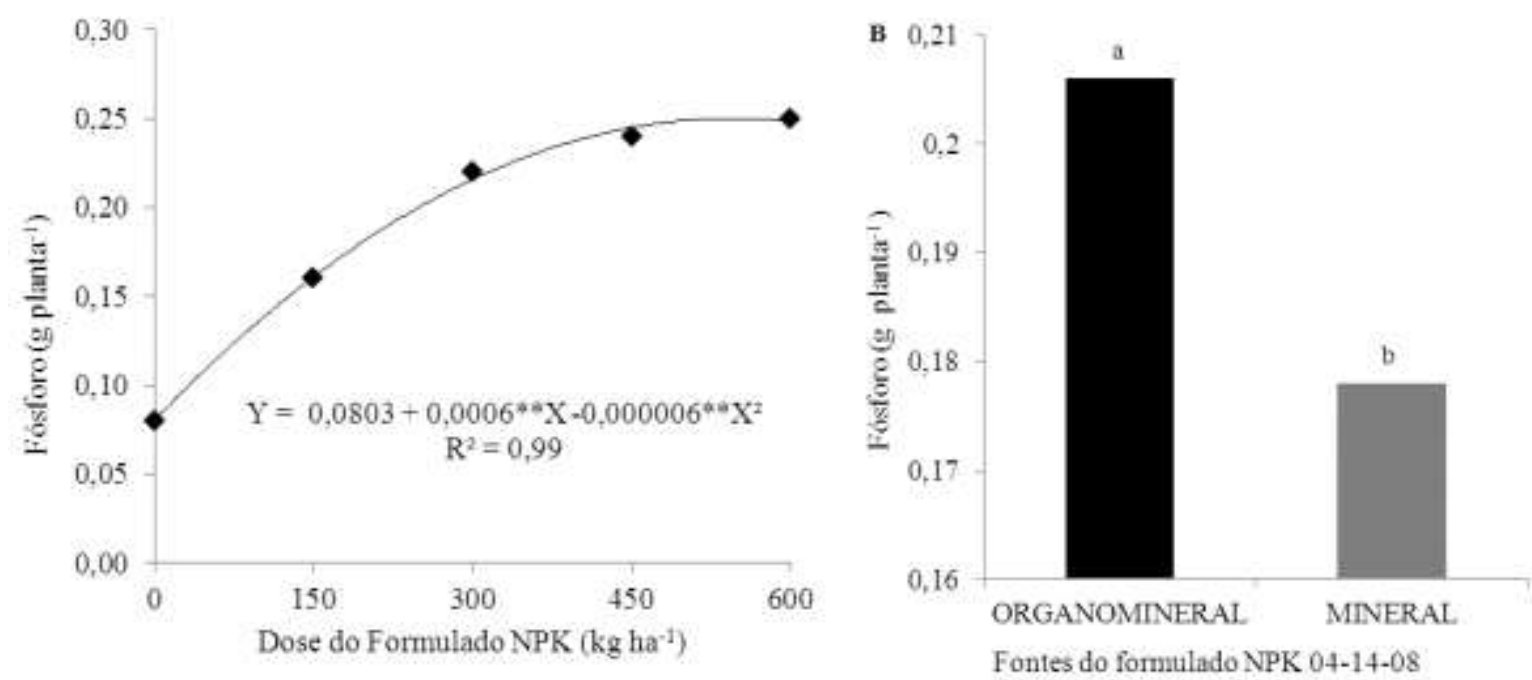

Médias seguidas com letras distintas na coluna, diferem entre si pelo teste de Tukey a 5\%. Fonte: Autores.

O fósforo acumulado na parte aérea do milho apresentou diferença significativa entre as fontes mineral e organomineral. (Figura 4B), cuja fonte organomineral proporcionou maior teor do nutriente comparada á fonte mineral. Semelhantemente Tiritan et al. (2010), avaliando adubação mineral e organomineral quanto ao teor de fósforo na matéria seca do milho, também verificaram acréscimo 36 gramas de fósforo por quilograma de matéria seca pela fonte organomineral. Tal fato pode ser explicado pelos fertilizantes organominerais apresentarem ácidos húmicos provenientes de sua parte orgânica, que podem ter contribuído para menor adsorção de $\mathrm{P}$, com liberação gradativa de $\mathrm{P}$ para a solução do solo, assim, aumentando o teor de P disponível à absorção e, consequentemente na parte aérea da planta (Tiritan et al., 2010; Lana et al., 2014).

Quanto o macronutriente potássio, a interação entre fonte e dose de formulado, pode mostrar a melhor dose correspondente para cada fonte e melhor fonte dentro de cada doses. Houve acréscimos com doses de formulado NPK para fonte organomineral até $600 \mathrm{~kg} \mathrm{ha}^{-1}$, cuja aplicação dessa dose do formulado NPK foi atingido acúmulo máximo, que foi de aproximadamente $3,7 \mathrm{~g}$ vaso $^{-1}$, o que equivale a $45 \%$ superior à dose de $150 \mathrm{~kg} \mathrm{ha}^{-1}$. As doses de formulado NPK para fonte mineral apresentou uma curva quadrática, cujos valores elevaram até a dose de $550 \mathrm{~kg} \mathrm{ha}^{-1}$, em que o acúmulo de 2,63 $\mathrm{g}_{\text {vaso }}{ }^{-1}$ de potássio na matéria seca (Figura 5A). Assim, a fonte organomineral apresentou diferença significativa entre as doses de 300 e $600 \mathrm{~kg} \mathrm{ha}^{-1}$, equivalente a 18 e $9 \%$ maiores do que a fonte mineral nas respectivas doses (Figura 5B). 
Figura 5. Acúmulo de potássio da parte aérea de plantas de milho, em função da interação das doses do formulado NPK (A) e fontes mineral e organomineral (B).
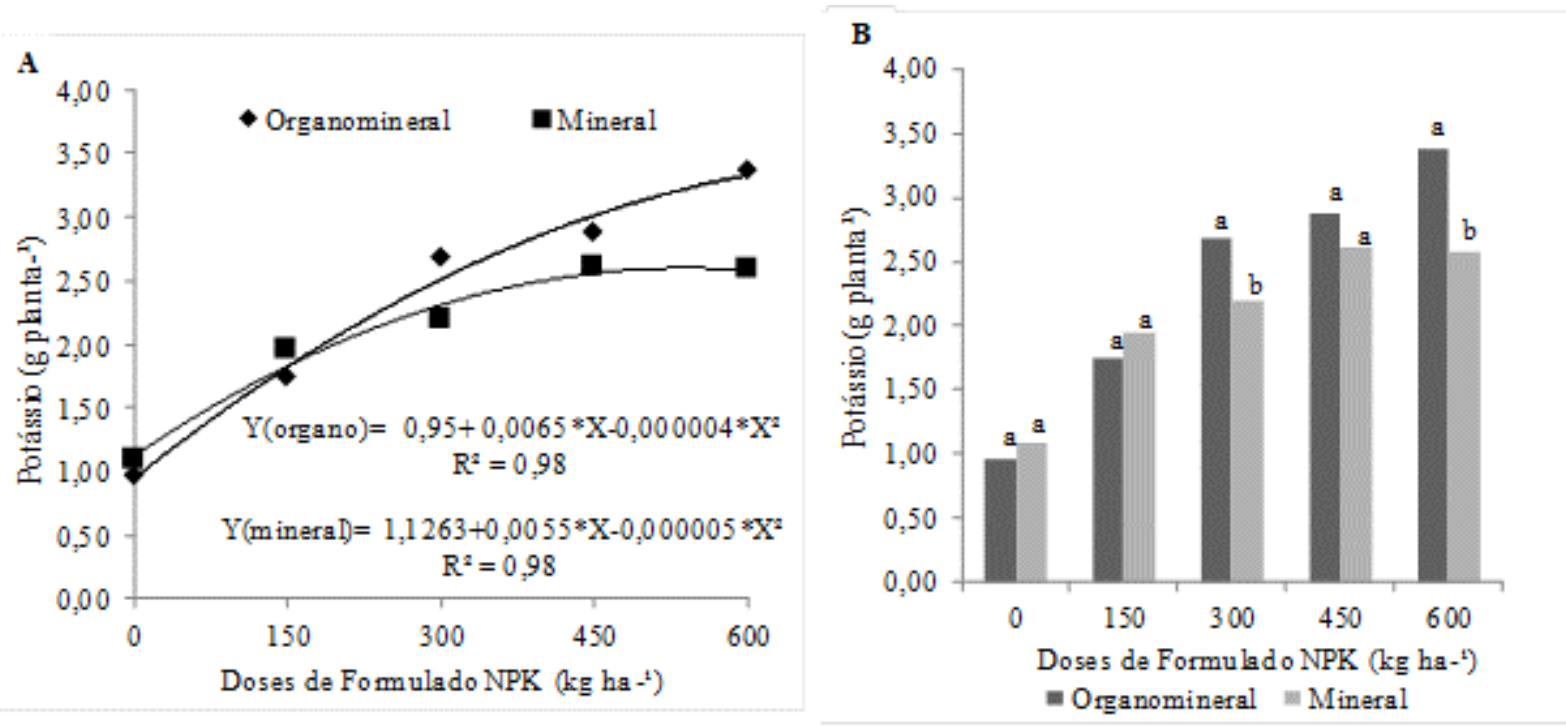

Médias seguidas com letra distintas na coluna, diferem entre si pelo teste de Tukey a 5\%. Fonte: Autores.

De acordo com a indicação de acúmulo de potássio considerado adequados na matéria seca do milho, os valores observados apresentaram nível baixo para milho (Malavolta et al., 1997). Justifica-se que absorção de K parece ter sido influenciada pela elevada disponibilidade de magnésio no solo, e pode ser decorrente do manejo da adubação. Dependendo das proporções presentes no solo, a interação entre esses cátions podem resultar em inibição competitiva daquele mais abundante sobre a absorção dos outros pelas plantas (Malavolta et al., 1997).

Estudo realizado por Borges (2006), avaliando a máxima absorção de potássio no milho no período a partir dos 56 dias, obteve acúmulo de $282 \mathrm{~kg} \mathrm{ha}^{-1}$, valor superior ao do presente estudo de $92 \mathrm{~kg} \mathrm{ha}^{-1}$. Essa superioridade pode estar relacionada, pois esse pico de absorção, ocorre perdas de potássio dos tecidos vegetais. Carvalho et al. (2014) relatam que a taxa de acúmulo médio diário de massa seca e macronutrientes pelas plantas de milho atingi o máximo aos 103 DAE, sendo que a colheita do milho no presente estudo foi realizada aos 75 DAE.

O máximo acúmulo para o nutriente cálcio foi obtido com a aplicação da maior dose de $600 \mathrm{~kg} \mathrm{ha}^{-1}$, que foi de aproximadamente $0,95 \mathrm{~g} \mathrm{vaso}^{-1}$ para fonte organomineral e de $0,89 \mathrm{~g} \mathrm{vaso}^{-1}$ para fonte mineral (Figura 6A). Cavalcante et al. (2012) relataram aumento de $0,48 \mathrm{~g} \mathrm{~kg}^{-1}$ de cálcio por cada aumento unitário de matéria orgânica, proveniente das fontes orgânicas cama de frango e esterco bovino. Os teores de cálcio da matéria seca das plantas apresentaram diferença significativa entre as fontes organomineral e mineral, nas doses de 450 e $600 \mathrm{~kg} \mathrm{ha}^{-1}$, cuja fonte organomineral proporcionou teores de Ca de 12,8 e 14,1\% maiores do que a fonte mineral, respectivamente (Figura 6B). 
Figura 6: Acúmulo de cálcio da parte aérea de plantas de milho, em função Interação das doses do formulado NPK (A) e fontes mineral e organomineral (B).
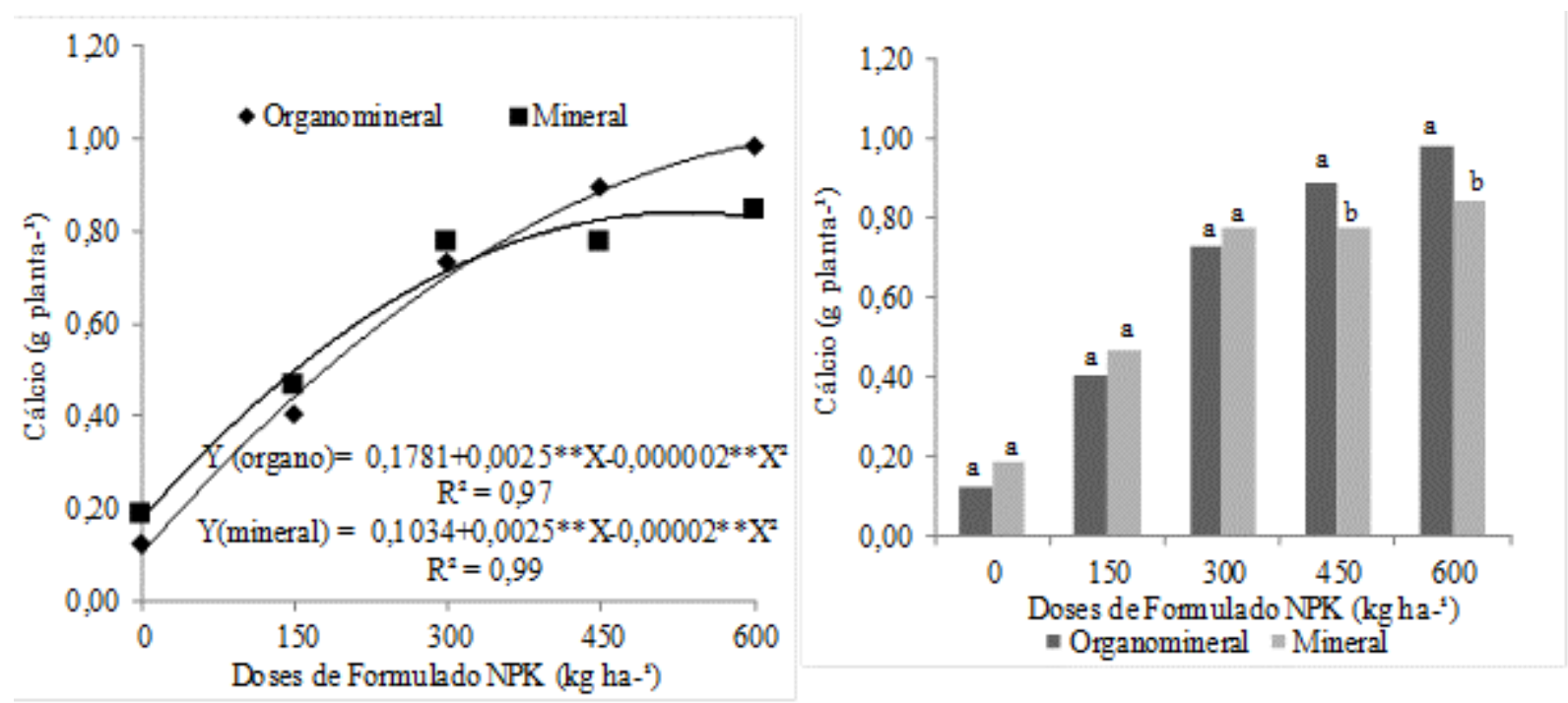

Médias seguidas com letra distintas na coluna, diferem entre si pelo teste de Tukey a 5\%. Fonte: Autores.

O acúmulo de nutrientes em porcentagens em matéria seca do milho para produção de grãos extrai de 3 a $7 \%$ de cálcio pelas plantas, assim o cálcio e o potássio são os nutrientes menos transloucados para os grãos, pois grande parte deles fica contida na palhada, que incorporada ao solo, que, por sua vez são mineralizados e restituídos ao solo (Coelho, 2006; Malavolta, 2006; Moreira, 2015).

Para magnésio, a utilização de doses crescentes de organomineral promoveu acréscimo linear no acúmulo deste elemento na planta. Já para a fonte mineral, constatou-se efeito quadrático no acúmulo de Mg na planta em função do aumento das doses de formulado NPK (Figura 7A).

Figura 7: Acúmulo de magnésio da parte aérea de plantas de milho, em função da interação das doses do formulado NPK (A) e fontes mineral e organomineral $(\mathrm{B})$.
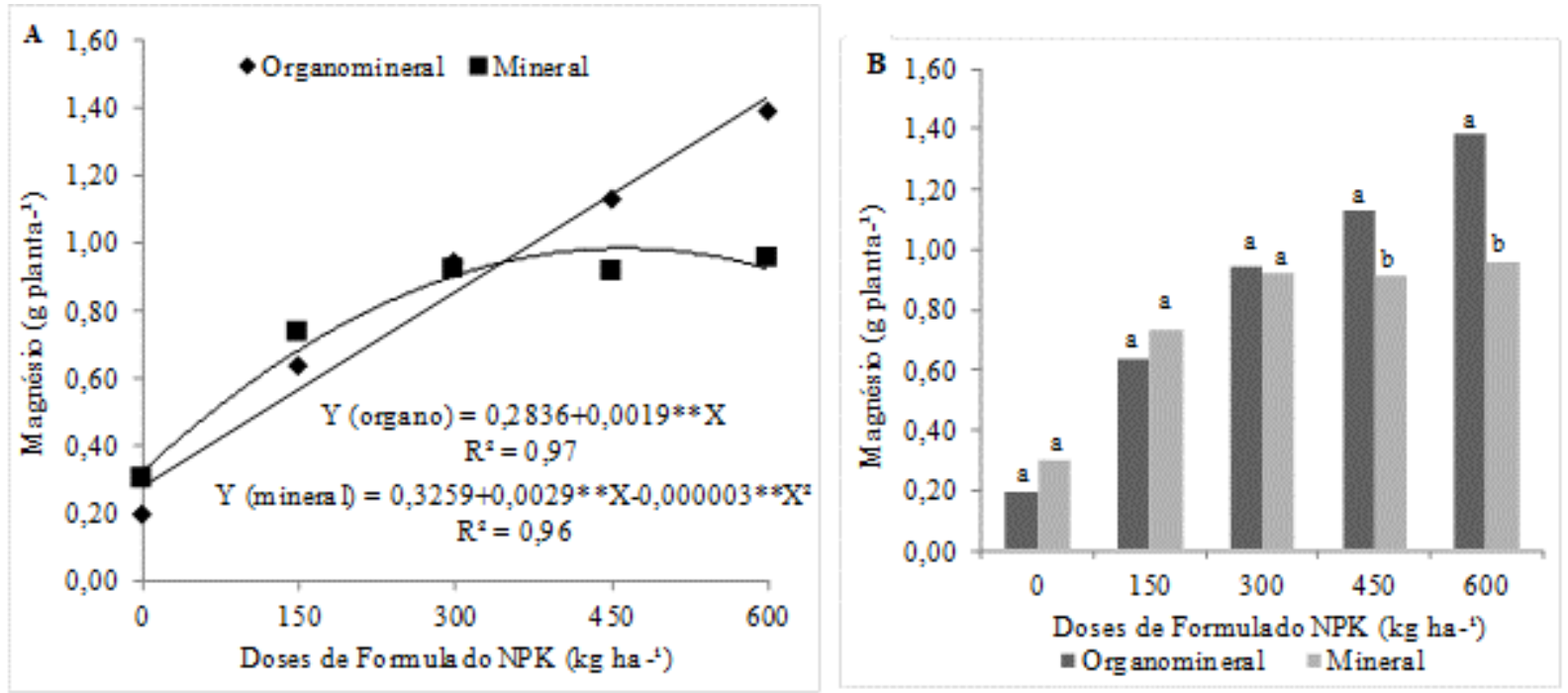

Médias seguidas com letra distintas na coluna, diferem entre si pelo teste de Tukey a 5\%. Fonte: Autores. 
Com relação à interação dos fatores doses e fontes de formulados, verifica-se efeito significativo, com maior acúmulo nas plantas. Independentemente da fonte NPK, o acúmulo de Mg na parte aérea das plantas aumentou com os incrementos das doses (Figura 7A), o que evidencia que a dose de $600 \mathrm{~kg} \mathrm{ha}^{-1}$ foi intensamente absorvido pelas plantas, sendo com aplicação dessa dose do formulado NPK foi atingida o acúmulo máximo de 1,42 e 1,00 g vaso-1 com fonte organomineral e mineral, respectivamente. As fontes mineral e organomineral apresentaram diferenças significativas nas doses de 450 e $600 \mathrm{~kg} \mathrm{ha}^{-1}$, cuja fonte organomineral apresentou teores de 19 e $31 \%$ maiores do que a fonte mineral, respectivamente (Figura 7B).

O teor de Mg na matéria seca das plantas de milho considerado alto (Malavolta, 2017), sendo o terceiro nutriente mais acumulado nas plantas. Marcela (2014) relatou que as quantidades de Mg acumulada pelas plantas decresceram com aumento das doses de manipueira prejudicou a absorção de Mg pelas plantas.

O acúmulo de enxofre (S) na matéria seca pelas plantas de milho em função das doses do formulado NPK para organomineral e mineral adequaram-se ao modelo quadrático, com $\mathrm{R}^{2}$ acima de $99 \%$ (Figura 8). Observa-se que para fonte mineral elevou até a dose $600 \mathrm{~kg} \mathrm{ha}^{-1}$. Com aplicação dessa dose do formulado NPK, foi atingida o acúmulo máximo de aproximadamente $0,30 \mathrm{~g} \mathrm{planta}^{-1}$, que corresponde a $81,44,17$ e $3 \%$ maior do que acúmulo observado nas doses do formulado NPK de 0, 150, 300 e $450 \mathrm{~kg} \mathrm{ha}^{-1}$, respectivamente (Figura 8A).

Figura 8: Acúmulo de enxofre da parte aérea de plantas de milho, em função da interação das doses do formulado NPK (A) e fontes mineral e organomineral (B).
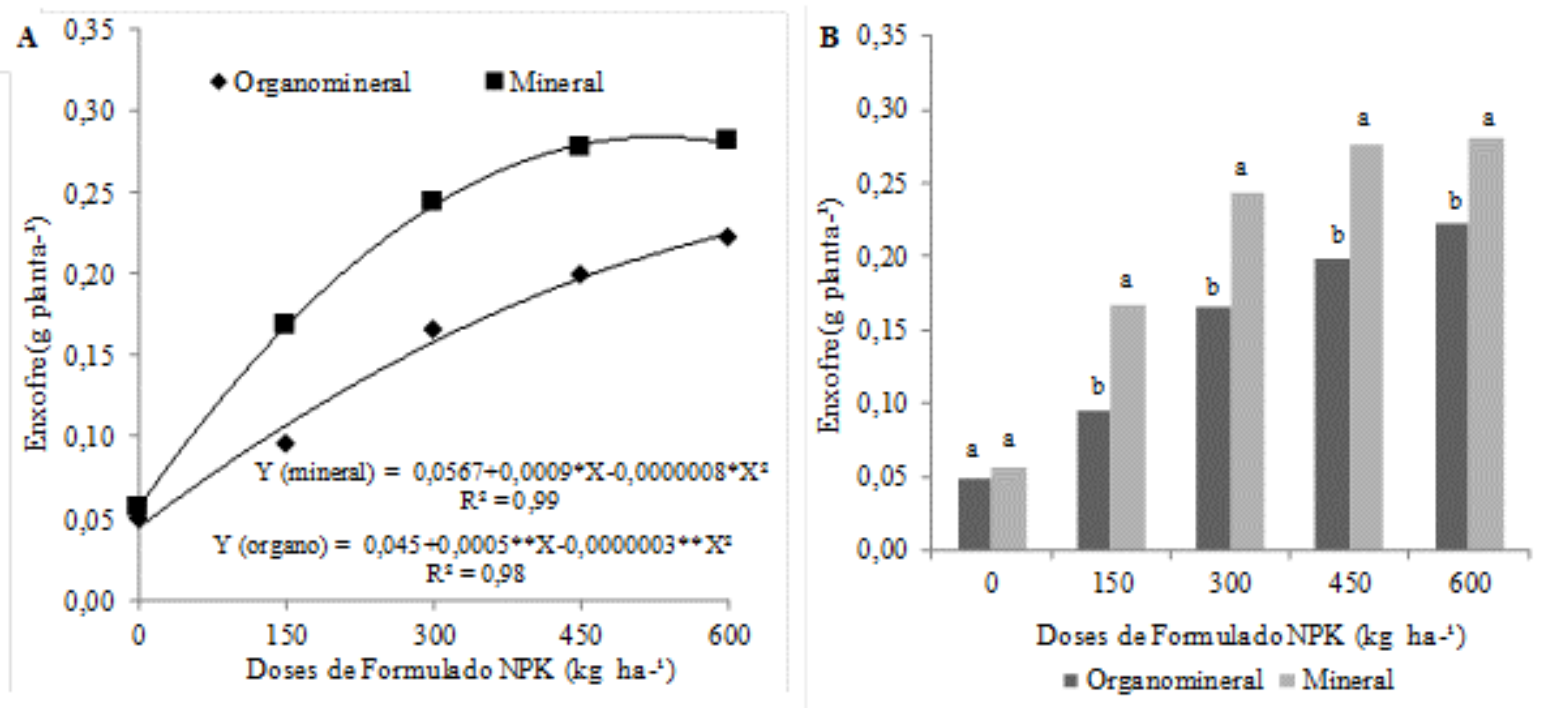

Médias seguidas com letra distintas na coluna, diferem entre si pelo teste de Tukey a 5\%. Fonte: Autores.

As doses de formulado NPK para fonte organomineral adequaram-se ao modelo quadrático, com $\mathrm{R}^{2}$ acima de $99 \%$, e houve acúmulo de enxofre até a dose $600 \mathrm{~kg} \mathrm{ha}^{-1}$, foi atingido o acúmulo máximo de aproximadamente 0,23 g planta-1 (Figura 8A). O acúmulo de enxofre máxima verificada na dose $600 \mathrm{~kg} \mathrm{ha}^{-1}$ foi $81,52,29$ e $11 \%$ maior do que observada nas doses do formulado NPK de 0, 150, 300 e $450 \mathrm{~kg} \mathrm{ha}^{-1}$, respectivamente. Fiorini et al. (2017), encontraram maior acúmulo de enxofre em relação ao obtidos no presente estudo, de aproximadamente $0,25 \mathrm{~g}_{\text {planta }}{ }^{-1}$, em experimento realizado em vasos de $30 \mathrm{~L}$ de solo. Ressalta que no presente estudo foram usados vasos de $25 \mathrm{~L}$.

As doses de 150, 300, 450 e $600 \mathrm{~kg} \mathrm{ha}^{-1}$ apresentaram diferenças significativas entre as fontes mineral e organomineral. Verifica-se que com a fonte mineral os teores foram 43, 31, 28 e 99\% maiores do que com a fonte organomineral, nas doses de 150, 300, 450 e $600 \mathrm{~kg} \mathrm{ha}^{-1}$, respectivamente (Figura 8B). Vale destacar que no presente estudo foi utilizada a fórmula NPK 04-14-08, considerada de baixa concentração, obtida a partir de fontes que possui enxofre na 
composição. Provavelmente, a absorção de $\mathrm{S}$ foi favorecida pela maior quantidade deste nutriente presente no solo, na camada de 0 a $0,2 \mathrm{~m}$, pois após a realização do experimento, foi amostrado o solo dos vasos para cada tratamento, e a dose $600 \mathrm{~kg} \mathrm{ha}^{-1}$ apresentou, em média $30 \mathrm{mg} \mathrm{dm}^{-3}$, cujo teor considerado alto (> $10 \mathrm{mg} \mathrm{dm}^{-3}$ ) (Sousa; Lobato et al., 2004). Mendes et al. (2014) observaram aumento nos teores foliares com a maior quantidade de enxofre no solo.

De maneira geral, dentre os macronutrientes estudados, o $\mathrm{N}$ foi o que apresentou maior tendência de acúmulo na parte aérea da planta de milho, seguido do K, Mg, Ca, S e P. Soares et al. (2014), observaram uma ordem extração similares (N> $\mathrm{K}>\mathrm{Ca}>\mathrm{Mg}>\mathrm{P}>\mathrm{S}$ ) no acúmulo de macronutrientes.

Quanto ao acúmulo de micronutrientes cobre, zinco, manganês e ferro na matéria seca das plantas de milho, apresentaram efeitos significativos $(\mathrm{p}=0,01)$ somente para as doses crescentes de formulado NPK. $\mathrm{O}$ acúmulo de cobre na matéria seca em função das doses apresentou uma curva quadrática, com máximo acúmulo na dose de $475 \mathrm{~kg} \mathrm{ha}^{-1}$ (Figura 9A).

Figura 9: Acúmulo de cobre (A), zinco (B) e manganês (C) na parte aérea de plantas de milho em função das doses do formulado NPK.
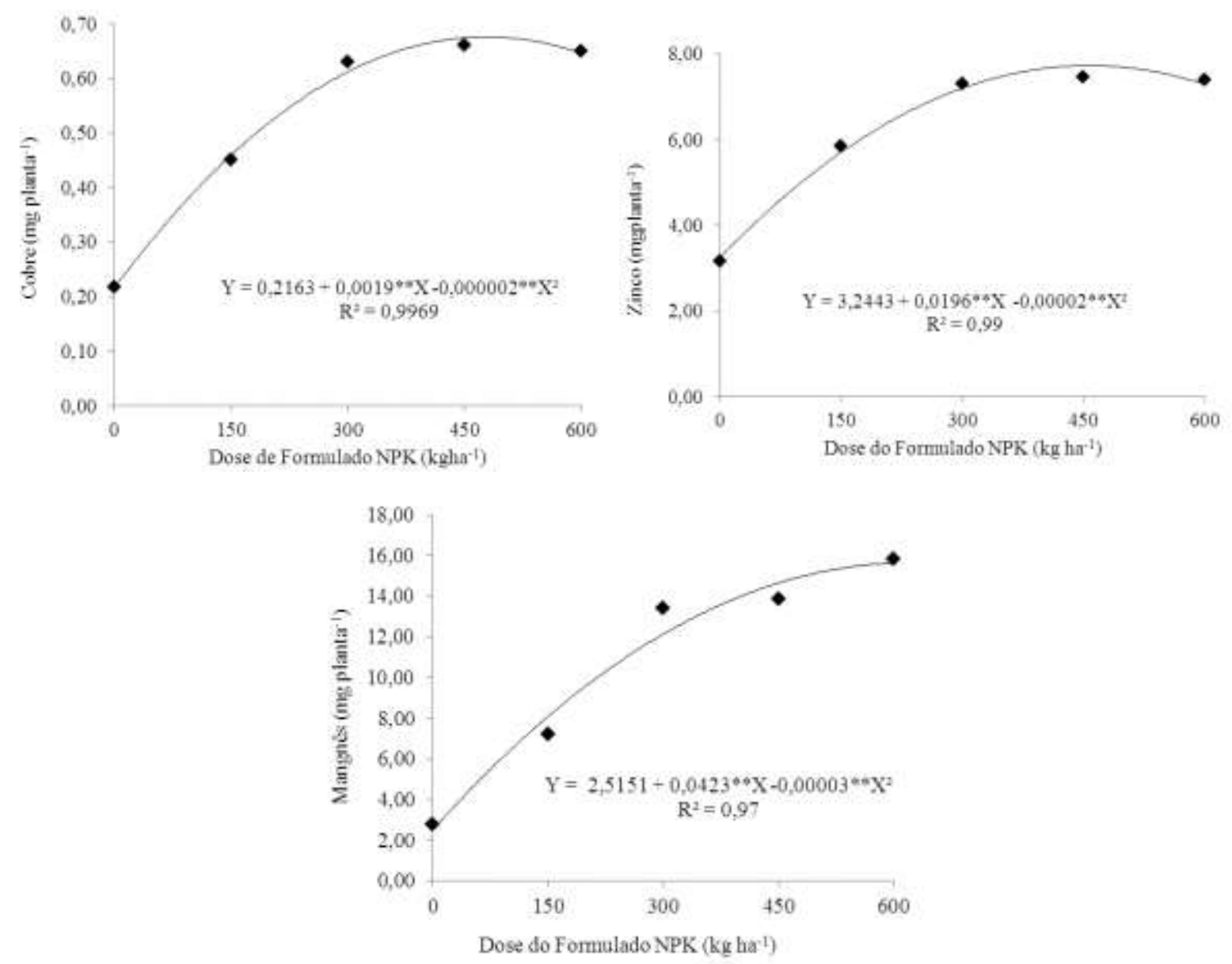

Fonte: Autores.

Em relação ao acúmulo de zinco (Zn) na matéria seca pelas plantas de milho em função das doses do formulados NPK organomineral e mineral adequou ao modelo quadrático, com ponto máximo na dose de $490 \mathrm{~kg} \mathrm{ha}^{-1}$, atingindo aproximadamente $8,0 \mathrm{mg} \mathrm{vaso}^{-1}$ Figura 9B. Isto sugere que, pelas condições de fertilidade do solo determinadas, doses mais altas poderiam implicar "consumo de luxo" desse nutriente, isto que seriam absorvidas sem que tenha havido ganho 
compensatório de fitomassa (Resende et al., 2016). Para acúmulo de manganês seguiu comportamento crescente de absorção com aumento das doses do formulado NPK (Figura 9C).

Quanto ao acúmulo do micronutriente ferro, ocorreu diferença significativa para as doses e fontes, cujas doses crescentes de adubação elevaram o acúmulo de $\mathrm{Fe}$ até a dose estimada de $570 \mathrm{~kg} \mathrm{ha}^{-1}$, em que se atingiu acúmulo máximo de aproximadamente $86 \mathrm{mg} \mathrm{planta}^{-1}$ (Figura 10A). Os dados de extração total de Fe observados no presente trabalho, aproximamse do valor de $3000 \mathrm{~g} \mathrm{ha}^{-1}$, que são superiores à média de $1.100 \mathrm{~g} \mathrm{ha}^{-1}$ encontrada por Bender et al. (2013) em trabalho com híbridos transgênicos nos EUA. Mas encontram-se abaixo dos $3.296 \mathrm{~g} \mathrm{ha}^{-1}$ reportados por Duarte et al. (2003) como média de cultivares originadas de clima temperado e tropical, avaliadas no Brasil. Ao que tudo indica, os padrões de extração de Fe pelo milho podem ser bastante variáveis, de acordo com os ambientes, as condições de solo, os híbridos utilizados e outras práticas de manejo.

Figura 10: Acúmulo de ferro da parte aérea de plantas de milho, em função das doses do formulado NPK: (A). Média para o acúmulo de ferro em função das fontes do formulado NPK 04-14-08 mineral e organomineral (B).
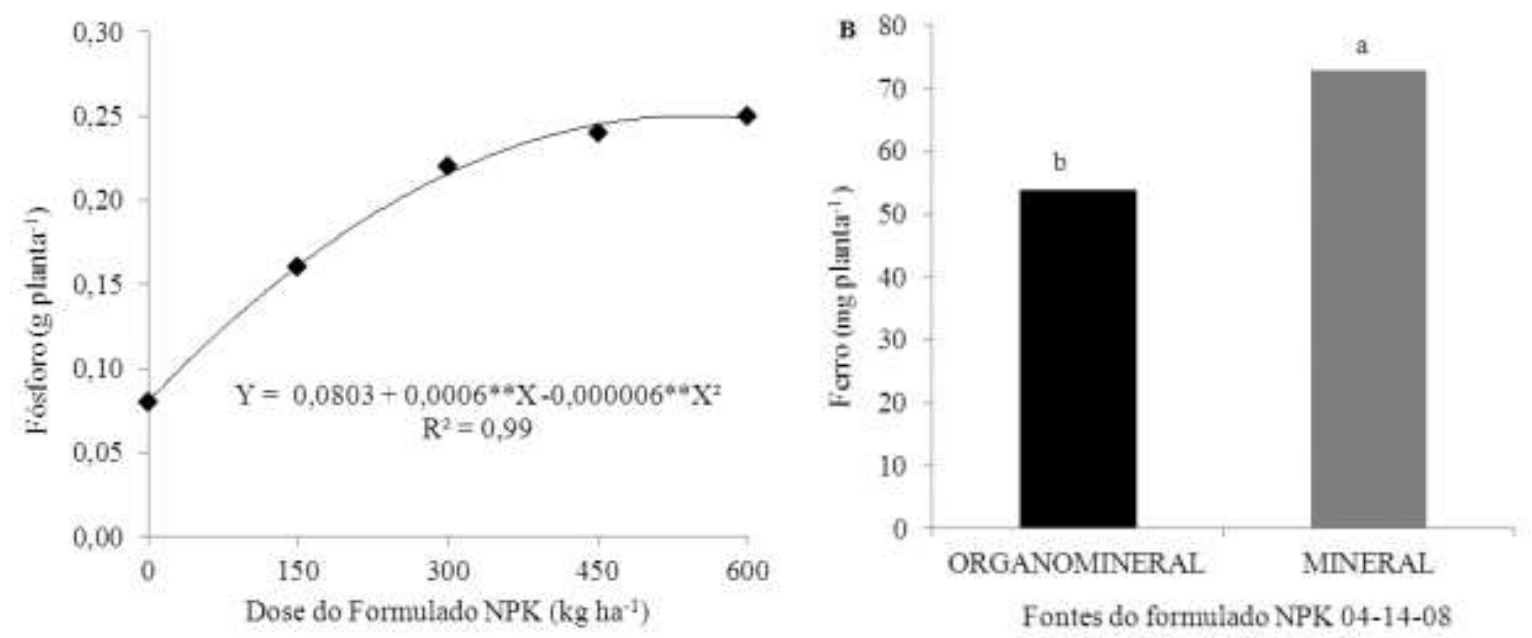

Médias seguidas com letras distintas na coluna, diferem entre si pelo teste de Tukey a 5\%. Fonte: Autores.

Comparando-se as fontes mineral e organomineral (Figura 10B), verifica-se que o acúmulo de ferro pela fonte mineral foi $26 \%$ maior àquele da fonte organomineral. Isto, possivelmente pelo alto teor de ferro liberada para o solo, seja, provavelmente em razão da sua alta disponibilidade no solo (Silva et al. 2017). Evidencia-se, assim, que as folhas e o colmo constituem os principais locais de deposição do Fe absorvido pelo milho, enquanto os grãos não representam forte dreno desse micronutriente. Bender et al. (2013) detectaram que mais de dois terços da extração total de Fe aconteceu antes da floração; porém, a extração máxima se deu entre o pendoamento (VT) e o início de enchimento do grão (R1).

Os resultados do presente estudo evidenciam que a fonte organomineral constitui em alternativa à adubação mineral, configurando uma prática importante para a reciclagem de nutrientes de fontes orgânicas, assim como menor dependência de fertilizante minerais, cuja maior parte usada no Brasil é importada e tem custo elevado. Assim, faz-se necessária a divulgação e ampliação de estudos na busca de incremento da produtividade com sustentabilidade econômica e ambiental.

\section{Conclusão}

A fonte organomineral NPK proporcionou maior produtividade de matéria seca ao milho, com a aplicação de doses acima de $300 \mathrm{~kg} \mathrm{ha}^{-1}$, comparada a fonte mineral. 
O fertilizante organomineral, nas mesmas doses de NPK, apresenta potencial de substituir as fontes minerais. $\mathrm{O}$ acúmulo de nutrientes seguiu a ordem decrescente $\mathrm{N}>\mathrm{K}>\mathrm{Mg}>\mathrm{Ca}>\mathrm{S}>\mathrm{P}>\mathrm{Fe}>\mathrm{Mn}>\mathrm{Zn}>\mathrm{Cu}$.

A fonte organomineral proporciona maior acúmulo de fósforo às plantas de milho, enquanto a fonte mineral maior.

\section{Agradecimentos}

Os autores agradecem ao Conselho Nacional de Desenvolvimento Científico e Tecnológico (CNPq); à Coordenação de Aperfeiçoamento de Pessoal de Nível Superior (CAPES) e à Fundação de Amparo à Pesquisa do Estado de Goiás (FAPEG), pelo apoio financeiro e estrutural.

\section{Referências}

Anderson, C. R., Hamonts, K., Clough, T. J., Condron, L. M., Fiers, M., Stewart, A., Hill, R. A., \& Sherlock, R. R. (2011). Biochar induced soil microbial community change: Implications for biogeochemical cycling of carbon, nitrogen and phosphorus. Pedobiologia, 54 (56), 309-320.

Atkinson, C. J., Fitzgerald, J. D., \& Hipps, N. A. (2010). Potential mechanisms for achieving agricultural benefits from biochar application to temperate soils: a review. Plant and Soil, 337 (1), 1-8.

Barretos, M. T. L., Magalhães, A. G., Rolim, M. M., Pedrosa, E. M. R., Duarte, A de S., \& Tavares, E. U. (2014). Desenvolvimento e acúmulo de macronutrientes em plantas de milho biofertilizadas com manipueira. Revista Brasileira de Engenharia Agrícola e Ambiental, 18 (5), $487-494$.

Bender, R. R., Haegele, J. W., Ruffo, M. L., \& Below, F. E. (2013). Nutrient uptake, partitioning, and remobilization in modern, transgenic insect-protected maize hybrids. Agronomy Journal, 105 (1), 161-170.

Benites, V. M., Correa, J. C., Menezes, J. F. S., \& Polidoro, J. C. (2010). Produção de fertilizante organomineral granulado a partir de dejetos de suínos e aves no Brasil. In: XXIX Reunião Brasileira de Fertilidade de Solo e Nutrição de Planta. FERTBIO, Guarapari - ES.

Benites, W. M., Correa, J. C., Menezes, J. F. S., Polidoro, J. C, (2010). Produção de fertilizante organomineral granulado a partir de dejetos de suínos e aves no Brasil. FERT BIO, 5 p.

Bernardi, A. C. C., Machado, P. L. O. A., Madari, B. E., Tavares, S. R. de. L., De Campos, D. V. B., \& Crisóstomo, L. de A. (2007). Carbon and nitrogen stocks of na arenosol under irrigated fruit orchards in semiarid Brazil. Scientia Agricola, 64 (2), 169-175.

Borges, I. D., Von Pinho, R. G., Pereira, J. L. A. R. (2009). Micronutrients accumulation at diferente maize development stages. Ciência e Agrotecnologia, Lavras, 33 (4), 1018-1025.

Brito, S. S., \& Santos, A. C (2010). Decomposição e mineralização de nutrientes em função da aplicação de diferentes fontes de matéria orgânica. Enciclopédia Biosfera, 6 (10), 1-8.

Carvalho, L. B., Bianco, S., \& Bianco, M. S. (2014). Estudo comparativo do acúmulo de massa seca e macronutrientes por plantas de Zea mays e Ipomoea hederifolia. Planta Daninha, 32 (1), 99-107.

Castoldi, G., Costa, M. S. S. M., Costa, L. A. M., Pivetta, L. P., \& Steiner, F. (2011). Sistemas de cultivo e uso de diferentes adubos na produção de silagem e grãos de milho. Acta Scientiarum, 33 (1), 139-146.

Castoldi, G., Costa, M. S. S. M., Costa, L. A. M., Pivetta, L. A., \& Steiner, F. (2011). Sistemas de cultivo e uso de diferentes adubos na produção de silagem e grãos de milho. Acta Scientiarum Agronomy, 33 (1), 139-146.

Castro Neto, P. (1982). Notas de aula prática do curso de agrometeorologia. Lavras, ESAL, p. 45.

Cavalcante, IHL (2012). Estado nutricional de pinheira sob adubação orgânica do solo. Revista Ciência Agronômica, 43 (3), $579-588$.

Cavalcante, L. F., Pereira, W. E., Curvêlo, C. R. S., Nascimento, J. A. M., \& Coelho, A. M. (2006). Nutrição e adubação do milho. Circular técnico, p. 78.

Costa, M. S. S. M., Steiner, F., Costa, L. A. M., Castoldi, G., \& Pivetta, L. A. (2011). Nutrição e produtividade da cultura do milho em sistemas de culturas e fontes de adubação. Revista Ceres, 58 (2), 249-255.

Duarte, A. P., Kiehl, J. C., Camargo, M. A. F., \& Reco, P. C. (2003). Acúmulo de matéria seco e nutriente em cultivares de milho originaria de clima tropical e introduzido de clima temperado. Revista brasileira de milho e sorgo, 2 (3), 1-20.

Farrell, M., Macdonald, L. M., Butler, G., Chirino-Valle, I., \& Condron, L. M. (2014). Biochar and fertiliser applications influence phosphorus fractionation and wheat yield. Biology and Fertility of Soils, Springer, Berlin, 50 (1), 169-178.

Fiorini, I. V. A., Pinho, R. G. V., Pereira, H. D., Pires, L. P. M., Fiorini, F. V. A., \& Resende, E. L. (2017). Acúmulo de matéria seca, clorofila e enxofre foliar em milho adubado com diferentes fontes de enxofre. Jornal Bioenergy and Food Science, 4 (1), 1-11.

França, G. E., \& Coelho, A. M. (2001). Adubação do milho para silagem. In: Cruz, J. C., Preira Filho, I. A., Rodrigues, J. A., \& Ferreira, J. J. (Ed.). Produção e utilização de silagem de milho e sorgo. Embrapa Milho e Sorgo, 53-83 p. 
Hickmann, C. (2014). Dinâmica de nitrogênio e ajustes na adubação NPK para uma sequência milho-soja-milho na região dos Campos das Vertentes. 159 p. Tese (Ciências Agrárias) apresentado a Universidade Federal de Lavras, Minas Gerais Lavras, UFLA

Jeffery, S., Verheijen, F. G. A., Velde, M. V. D., \& Bastos, A. C. Quantitative review of the effects of biochar application to soils on crop productivity using metaanalysis. Agriculture, Ecosystems \& Environment, Elsevier, 144 (1), 175-187.

Lana, M. C., Rampim, L., Schulz, L. R., Kaefer, J. E., Hartmann-Schimidt, M. A., \& Ruppenthal, V. (2014). Disponibilidade de fósforo para plantas de milho cultivadas com fertilizante organomineral e fosfato monoamônico. Scientia Agraria Paranaensis, 13 (3), 198-209.

Lana, M. C., Rampim, L., \& Vargas, G. (2014). Adubação fosfatada no milho com fertilizante organomineral em latossolo vermelho eutroférrico. Global Science and Technology. Rio Verde, 07 (01), 26-36.

Levrero, C. R. (2009). Fertilizante organomineral: a serviço do mundo. Fórum Abisolo.

LOPES, A. S., et al. Suprimento e extensão das reservas de nutrientes no Brasil (2010). In: Prochnow, L., Casarin, V., \& Stipp, S. .R (Ed.). Boas práticas para uso eficiente de fertilizantes. Piracicaba: IPNI, 283-307.

Lourente, E. R. P., Mercante, F. M., Alovisi, A. M. T., Gomes, C. F., Gasparini, A. S., \& Nunes, C. M. (2011). Atributos microbiológicos, químicos e físicos de solo sob diferentes sistemas de manejo e condições de cerrado. Pesquisa Agropecuária Tropical, Goiânia, 41 (1), 20-28.

Malaquias, C. A. A., \& Santos, A. J. M. (2017). Adubação organomineral e NPK na cultura do milho. PUBVET, 11 (5) 501-512.

Malavolta, E. Manual de nutrição mineral de plantas: Ed. Cerres, 2006.

Malavolta, E., Vitti, G. C., \& Oliveira, A. S. (1997). Avaliação do estado nutricional de plantas: princípios e aplicações: Potafos, 319 p.

Mendes, M. C., Walter, A. L. B., Possato Junior, O., Rizzardi, D. A., Schlosser, J., \& Szeuczuk, K. Dose de nitrogênio associado a enxofre elementar em cobertura na cultura do milho em plantio direto. Revista Brasileira de Milho Sorgo, 13 (1), 96-106.

Ministério da Agricultura Pecuária e Abastecimento. Secretaria de Defesa Agropecuária. Instrução Normativa no 25 de 23 de julho de 2009. Diário Oficial, Brasília, DF, n. 142, 28 jul. 2009. Seção 1, p. 20.

Ministério da Agricultura, Pecuária e Abastecimento. Instrução normativa $\mathrm{n}^{\mathrm{o}} 25$, de 23 de julho de 2009. (2009) Brasília, DF. https://www.embrapa.br/documents/1355242/0/Biog\%C3\%A1sFert+-

+Instru\%C3\% A7\%C3\%A3o+Normativa+25\%2C+normas+sobre+fertilizantes+destinados+\%C3\%A0+agricultura.pdf.

Moreira, J. C. Accumulation of dry matter and nutrients in sweetcorn crops. (2015). 56 f. Dissertação (Mestrado em Agricultura Tropical) - Universidade Federal Rural do Semi-Árido, Mossoró.

Nelissen, V., Rutting, T., Huygens, D., Staelens, J., Ruysschaert, G., \& Teixeira, W. G (2012). Maize biochars accelerate short-term soil nitrogen dynamics in a loamy sand soil. Soil Biology \& Biochemistry, 55 (1),20-27.

Novais, R. F., Alvarez V. V. H., Barros, N. F., Fontes, R. L., Cantarutti, R. B., \& Lima, J. C. (2007). Fertilidade do solo. In: Alvarez VVH. Fertilizantes. 737 769.

Ourives, O. E. A., Souza, G. M., Tiritan, C. S., \& Santos, D. H. (2010). Fertilizante orgânico como fonte de fósforo no cultivo inicial de brachiaria brizantha cv. marandú. Pesq. Agropec. Tropical., 40 (2), 126-132.

Peixoto, T. D. C. (2014). Análise de adubações e espaçamento entre linhas nas características biométricas e de produtividade do milho. 59f. Dissertação (Manejo de solo e água) apresentado a Universidade Federal Rural do Semi-árido, Mossoró, UFERSA.

Pinho, R. G. V., Borges, I. D., Andrade, J. L., \& Dos Reis, M. C. (2009). Marcha de absorção de macronutrientes e acúmulo de matéria seca em milho. Revista Brasileira de Milho e Sorgo, 8 (2), 157-173.

Raij, B. V., Andrade, J. C., Cantarella, H, \& Quaggio, J. A. (2001). Análise química para avaliação da fertilidade de solos tropicais. Campinas: Instituto Agronômico, 285 p.

Ramos, L. A., Lana, R. M. Q., Korndörfer, G. H., \& Silva, A. A. (2017). Effect of organomineral fertilizer and poultry litter waste on sugarcane yield and some plant and soil chemical properties. African Journal of Agricultural Research, 12 (1) 20-27.

Resende, A. V., Gutierrez, A. M., Silva, C. G. M., Almeida, G. O., Guimarães, P. E. de O., Moreira, S. G., \& Neto, M. M. G. (2016). Requerimentos nutricionais do milho para produção de silagem. Sete Lagoas: Embrapa Milho e Sorgo, (Circular Técnica, 221).

Rodrigues, T. R. D., Broetto, L., Oliveira, P. S. R., \& Rubio, F (2012). Desenvolvimento da cultura do milho submetida a fertilizantes orgânicos e minerais. Bioscience Journal, 28 (4), 509-514.

Santos, H. G., Jacomine, P. K. T., Anjos, L. H. C., Oliveira, V. A., Lumbreras, J. F., Coelho, M. R., Almeida, J. A., Araujo Filho, J. C., Oliveira, J. B., \& Cunha, T. J. F. (2018). Sistema Brasileiro de Classificação de Solo: Embrapa, (5 ed.)

Silva, M. S., Oliveira, G. R. F., \& Merloti, M. E. S. (2017). Acúmulo de nutrientes e massa seca produzida por crotalaria juncea cultivada no cerrado. Brazilian Journal of Biosystems Engineering, 11 (1), 26-36

Soares, E. R., Coutinho, E. L. M., Ramos, S. B., da Silva, M. S., \& Barbosa, J. C.. (2014). Acúmulo de matéria seca e macronutrientes por cultivares de sorgo sacarino. Ciências Agrárias, 35 (6), 3015-3010.

Souza, D. M. G., \& Lobato, E. (2013). Adubação fosfatada em solos da região do Cerrado. Informações Agronômicas, Encarte Técnico Planaltina, 102 (1), 116. 
Research, Society and Development, v. 10, n. 5, e35010515126, 2021

(CC BY 4.0) | ISSN 2525-3409 | DOI: http://dx.doi.org/10.33448/rsd-v10i5.15126

Timossi, P. C., Silva Júnior, H. R., \& Lima, S. F. (2016). Adubação antecipada com fertilizantes orgânico e mineral associado à crotalarias na cultura do milho. Revista Brasileira de Milho e Sorgo, 15 (3), 499-508.

Tiritan, C. S., Santos, D. H., Foloni, J. S. S., \& Júnior, R. A (2010). Adubação fosfatada mineral e organomineral no desenvolvimento do milho. Colloquium Agrariae, 6 (1), 08-14.

Vitti, G. C., Boaretto, A. E., \& Penteado, S. R. (1994). Fertilizantes e fertirrigação. In: simpósio brasileiro sobre fertilizantes fluídos, 1. Anais. Piracicaba: Associação Brasileira para Pesquisa do Potássio e do Fosfato, 261-280.

Wilda, R. L. M. (2014). Amostragem georreferenciada e aplicação à taxa variável de corretivos e fertilizantes: dinâmica da fertilidade do solo em lavoura de grãos do cerrado. 2014. 84 p. Dissertação (Mestrado em Ciência do Solo) - Universidade Federal de Lavras, Lavras. 